\title{
Finite Element Analysis of Loader Lift Arm
}

\author{
Fangqin Pan ${ }^{1, a}$, Huqi Wang ${ }^{2, b}$, Yupeng Yin ${ }^{3, c}$ and Aixia Yuan ${ }^{4, d}$ \\ ${ }^{1,2,3}$ School of Mechanical Engineering ,Guangxi University of Science and Technology, \\ Liuzhou,Guangxi, 545006, China

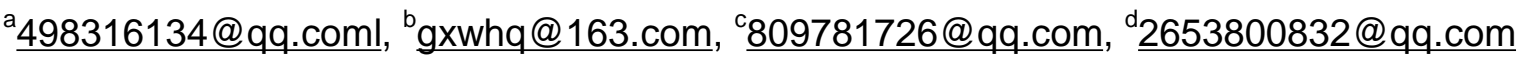

Keywords: loader lift arm, finite element analysis, modal analysis, natural frequency

Abstract: With the continuous development of science technology and society, machinery industry got the unprecedented development. Among them, the loader played an indispensable role. As a core part of the loader work, loader lift arm has the effect of bearing and transmission power. The loader lift arm often is damaged in work. The finite element analysis for loader lift arm is done by ANSYS software. The weak place is found by analysis of the displacement and stress nephogram. Meanwhile the natural frequencies of the loader lift arm are also got by modal analysis in ANSYS. These analysis results will be helpful for us to design new safe product and ovoid the occurrence of resonance.

\section{Introduction}

Loader is widely applied in the field of engineering because it has strong adaptation, high efficiency and application of common characteristics. As the research object, the stress and deformation of lift arm is calculated by ANSYS software in this paper. The dangerous section is got by analysis. We can improve the loading ability and prolong life by the design improvement according to the analysis result. At first loader lift arm is modeled in ANSYS, and a nearly realistic model is obtained. Then the model will be meshed and be given corresponding local restrictions and loads, and be solved. Under different working conditions stress nephogram and displacement nephogram can be got. Thus we can do analysis, evaluation, and timely finding the defects and weak links in order to put forward the optimization and improvement scheme. And it will not affect the entire product development and design cycle.

\section{The finite element static analysis of loader lift arm}

\section{Loader operating conditions under different circumstances.}

Loader as a kind of engineering machinery can do many works such as shovel, loading, transport, unloading and other several kinds of movements. The whole loop works include forward, shovel outfit, backward, steering, forward, discharge, etc. The main condition is when loader lift arm lifts up $15^{\circ}$ angle condition. So this condition was analyzed. Force diagram is shown in Fig. 1 and Fig. 2.

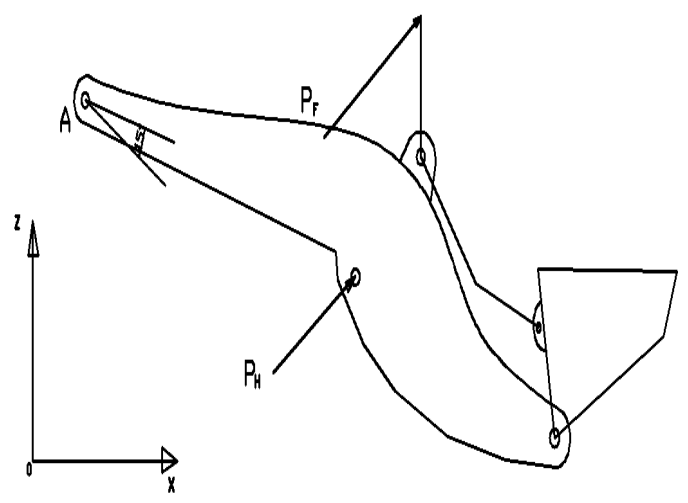

Fig1.The force diagram

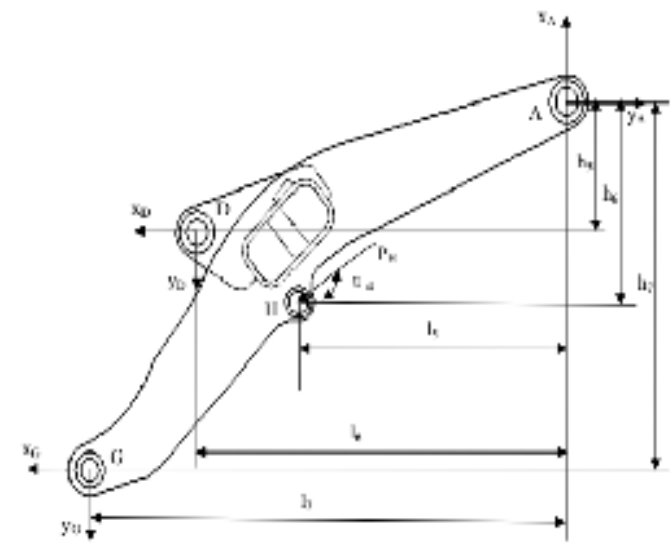

Fig.2. The force of lift arm 
By the figure 2, A point is the rotation of the arm fulcrum, PF is pulling force for turning oil cylinder are, PH point is lifting force of lifting cylinder .

$$
\begin{aligned}
& \text { By } \alpha_{1}=\alpha_{2}=23^{\circ}, \alpha_{4}=4^{\circ}, L_{D}=110.3(\mathrm{~mm}), l_{2}=281.9(\mathrm{~mm}), L_{3}=257.4(\mathrm{~mm}), \\
& L_{5}=1140(\mathrm{~mm}), L_{6}=1385(\mathrm{~mm}), L_{7}=1850.9(\mathrm{~mm}), h_{2}=232.9(\mathrm{~mm}), h_{3}=281.5(\mathrm{~mm}), \\
& h_{4}=453.5(\mathrm{~mm}), h_{5}=, 306.5(\mathrm{~mm}), h_{6}=649.7(\mathrm{~mm}), h_{7}=1115.4(\mathrm{~mm}) \\
& P_{C}=\frac{\frac{G}{2} L_{D}}{h_{2} \cos \alpha_{1}-l_{1} \sin \alpha_{1}}=10162(\mathrm{~N}) . \\
& X_{B}=P_{C} \operatorname{Cos} \alpha_{1}=10162 \operatorname{Cos} 23^{\circ}=9565.8(\mathrm{~N}) . \\
& Z_{D}=\frac{G}{2}-P_{C} \sin \alpha_{1}=10162 \sin 23^{\circ}=5740(\mathrm{~N}) . \\
& P_{F}=\frac{P_{D}\left(l_{4} \sin \alpha_{2}+h_{3} \cos \alpha_{2}\right)}{h_{4} \cos \alpha_{3}-L_{3} \sin \alpha_{3}}=11324(\mathrm{~N}) . \\
& X_{E}=P_{F} \cos \alpha_{3}+P_{D} \sin \alpha_{2}=21756.4(\mathrm{~N}) . \\
& Z_{E}=-P_{D} \sin \alpha_{2}+P_{F} \sin \alpha_{3}=-3125(\mathrm{~N}) . \\
& P_{H}=\frac{X_{E} h_{5}+Z_{E} L_{6}+X_{B} h_{7}-Z_{B} L_{7}}{h_{6} \cos \alpha_{4}+L_{5} \sin \alpha_{4}}=-27632.9(\mathrm{~N}) .
\end{aligned}
$$

The $\mathrm{X}$ axis is positive to the right direction, $\mathrm{Z}$ axis is positive upward direction, it can get to the hinge points of arm board: $X_{B}=9565.8(\mathrm{~N}), Z_{B}=5740(\mathrm{~N})$; the hinge points Support plate : $X_{E}=-21756.4(\mathrm{~N}), Z_{E}=-3125(\mathrm{~N})$; the hinge point of lifting cylinder of the arm : $X_{H}=27632.9, Z_{H}=1950.3(\mathrm{~N})$.

\section{The finite element model of loader lift arm}

The finite element model for loader lift arm model is built by using the bottom-up method in ANSYS software in order to analyze it. It is shown in Fig.3. Global Settings are used on arm mesh with the grid size of 20. It is shown in Fig.4.

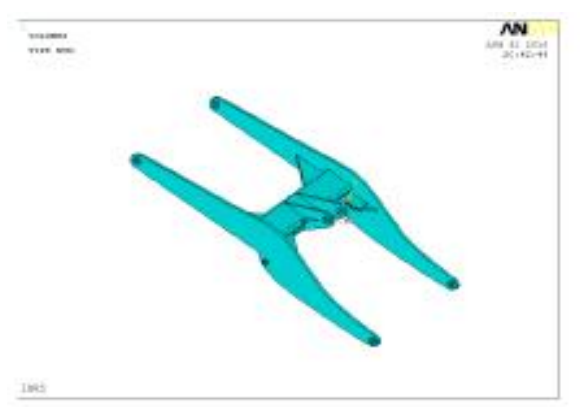

Fig3. The finite element model of arm

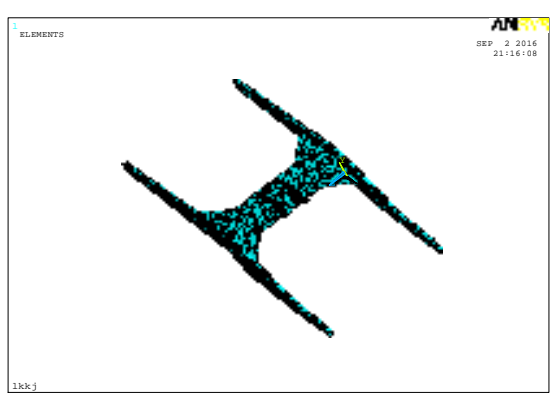

Fig4. Motor arm mesh model

\section{Boundary conditions and solving}

Constraint part is hinge point A of loader lift arm, all constraints are imposed on internal hole surface. It is shown in Fig.5. The load part is the loader lift arm hinge points P. It is shown in Fig.6. 


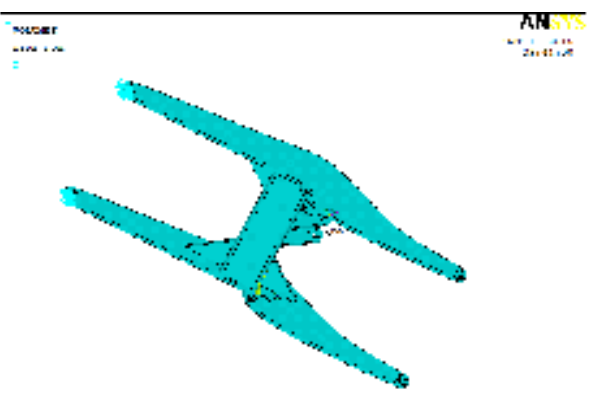

Fig5.The constraints of the loader lift arm

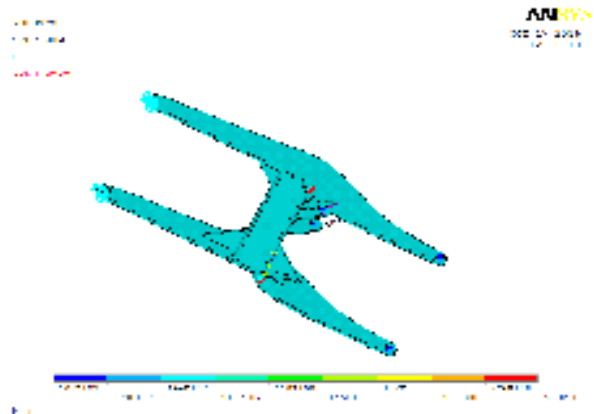

Fig6. Load of the loader lift arm

Displacement diagram and stress nephogram of the lift arm is got by the solution of ANSYS. It is shown in Fig.7 and Fig.8. The material of loader lift arm is $16 \mathrm{Mn}$, yield stress is $345 \mathrm{Mpa}$, safety coefficient is 1.5, and the allowable stress is $240 \mathrm{Mpa}$. It is shown in Fig.9 and Fig.10.

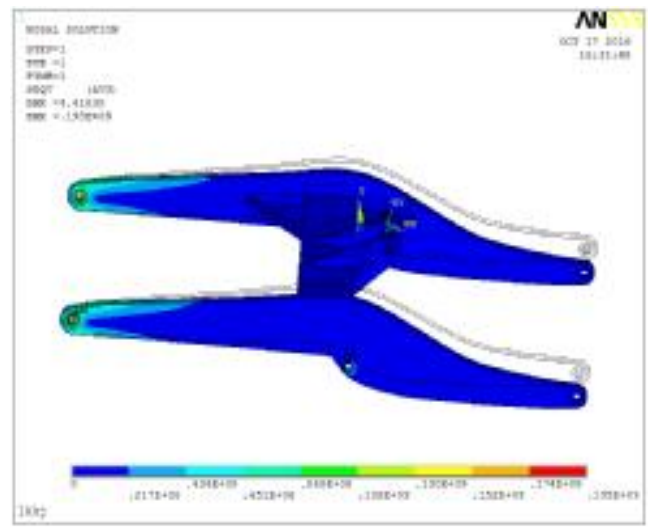

Fig7.Spading $15^{\circ}$ condition deformation

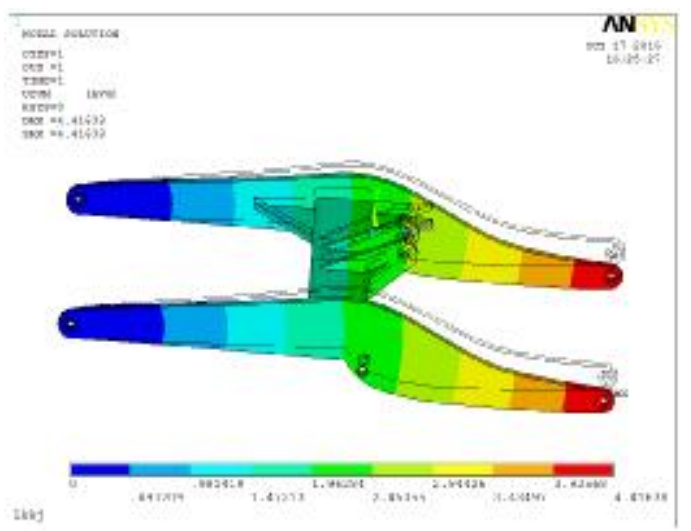



Figure 8.Excavation conditions

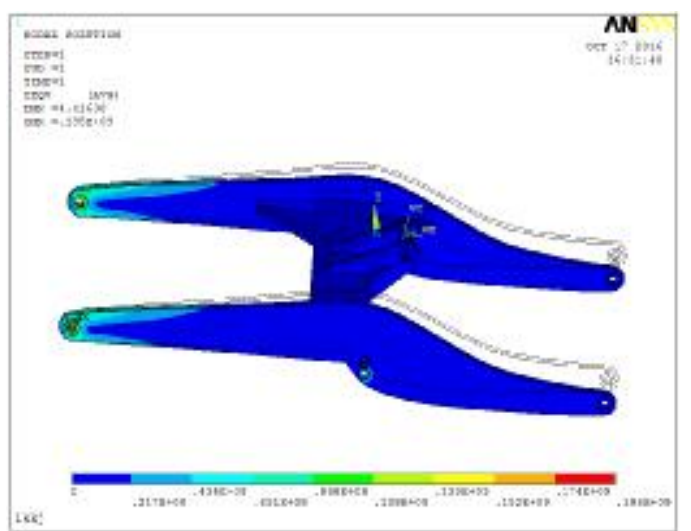

Figure 9. 15-degree displacement nephogram Figure 10.15-degree stress cloud nephogram From Fig.7, the stress of the lower arm, the beam, the rib and the supporting plate (blue area) is 0 to $16.7 \mathrm{Mpa}$, and the stress is small. The main stress concentration is mainly on the lift arm hinge point. The upper hole (yellow and red area) on the lift arm is $133 \mathrm{Mpa}$ to $150 \mathrm{Mpa}$, which is the most dangerous area, but not more than the allowable stress of $240 \mathrm{MPa}$.

\section{Modal analysis of loader lift arm impose constraints}

The analysis model was established in ANSYS. Constraints were imposed in the lift arm on the hinge point of the two holes after the definition of material properties, and meshing. It is shown in Fig.11. 


\section{Modal analysis results}

The first five natural frequencies shown in Fig.12were got from analysis. The smallest is $0.01717 \mathrm{~Hz}$.

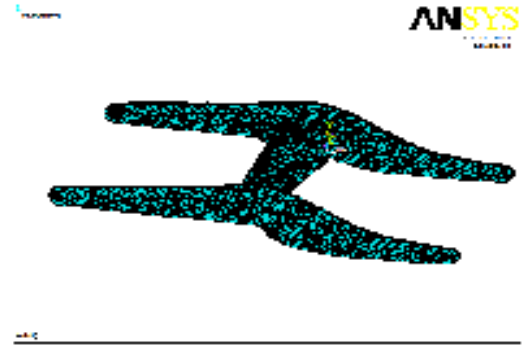

Figure 11. Apply constraints to the boom

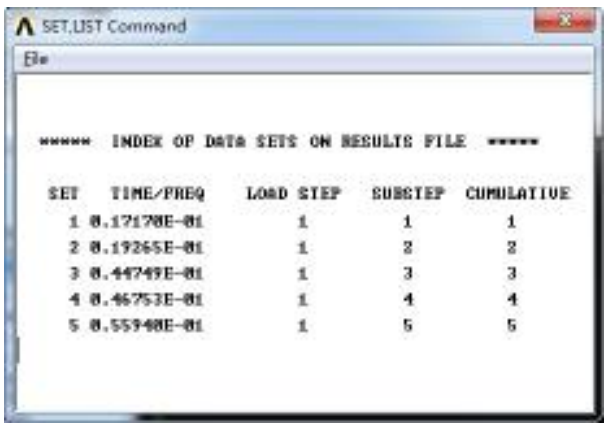

Figure 12. Natural frequency

The vibration modes of first four model were shown in Fig.13-14.

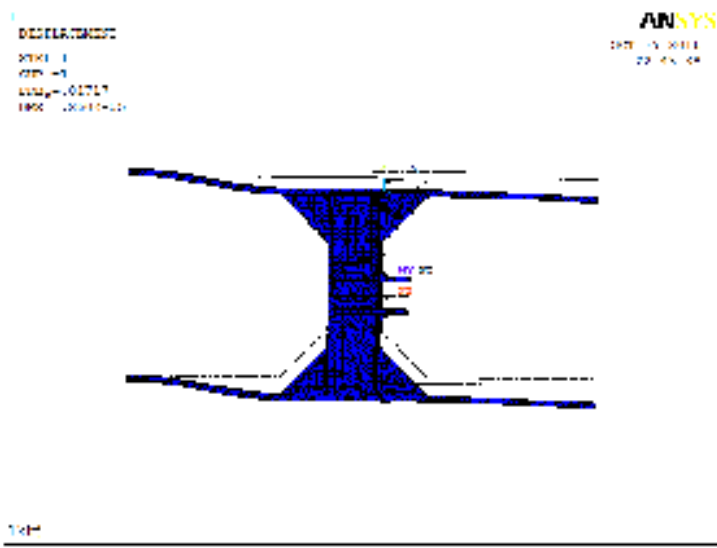

Figure 13. The first-order model

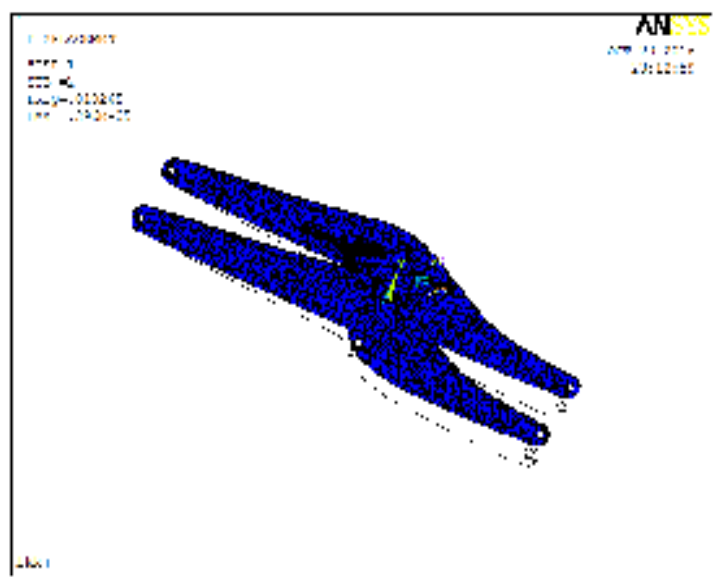

Figure 15 Third-order model
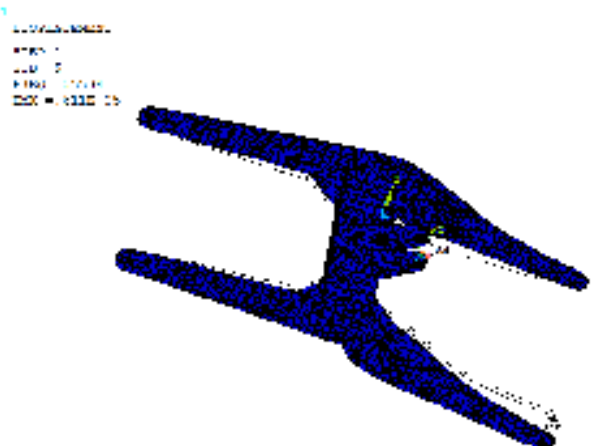

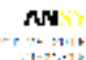

$$
\underline{1 \times<4}
$$

Figure 14. Second-order model

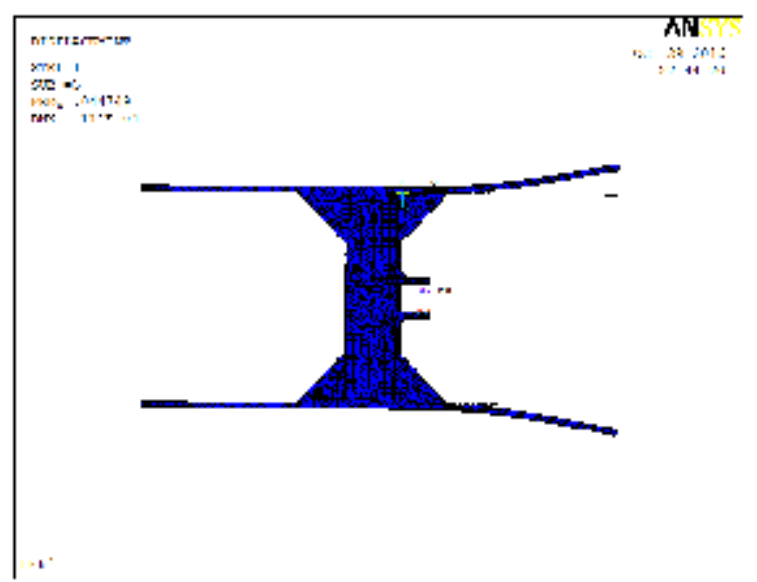

Figure 16. Fourth-order model

\section{Conclusions}

The weak place in the lift arm is found after the structural static analysis. It is good for our improvement of new loader. The natural frequency and vibration shape is got by the modal analysis. It can help us to avoid the resonance and the transformation in our new design.

\section{Acknowledgements}

This work was financially supported by the State Natural Science Foundation(51565006) and Doctor Foundation of Guangxi University of Science and Technology（11Z11）. 


\section{References}

[1] Weini Mo . Finite element analysis: ANSYS theory and application. Beijing: Electronics Industry Press, May 2013.

[2] Jitong Leng. Finite Element Technology Foundation. Beijing Chemical Industry, April, 2007.

[3] Zhaohui Zhang. ANSYS12.0 structural analysis of engineering application examples. Beijing. Mechanical Industry Press. January 2010.

[4] Shuguang Gong. ANSYS engineering application examples analysis. Beijing. Mechanical Industry Press . March 2003.

[5] Jingyi Chen. Computer-aided engineering analysis of the use of ANSYS. Beijing. China Railway Industry Press .March 2001. 